\title{
Case Report: \\ Hepatitis E Viral Infection after Kidney Transplantation. Guidelines Revisited
}

\author{
MOHSEN EL KOSSI, M.D.* and SANAA FADEL, Ph.D.** \\ Consultant Nephrologist Doncaster Royal Infirmary Hospital, Doncaster, UK* and \\ Department of Microbiology \& Immunology, Faculty of Pharmacy, Cairo University, Egypt**
}

\begin{abstract}
Clinical practice guidelines of hepatitis E treatment post solid organ transplantation would undoubtedly help improve management of these cases. Whilst hepatitis E viral infection runs a benign course in healthy individuals, it can lead to persistent hepatitis and liver cirrhosis in immunocompromised patients including patients with solid organ transplantation. Available treatment options of these cases lack supporting robust evidence and they are derived from limited number of case series. There are no randomised clinical trials that help inform clinicians' decision making. This results in some gaps in the current guidelines that may require further attention. We hereby present a kidney transplant recipient who developed hepatitis E viral infection. We will discuss his management in light of these gaps.
\end{abstract}

Key Words: Hepatitis E Viral Infection - Kidney Transplantation.

\section{Introduction}

HEPATITIS E infection is usually mild and selflimited in healthy individuals. This is largely different in patients with chronic liver disease and pregnant women $[\mathbf{1}, 2]$. Mortality rate in pregnancy could reach $25 \%$ [3]. Immunocompromised patients with solid organ or bone marrow transplantation are at a higher risk of developing persistent hepatitis E infection [4,5]. HEV strains infecting human are classified into four major genotypes (1 to 4) [6] . HEV3 is mainly transmitted by consumption of pig or game meat and is the prevalent genotype encountered in Europe. There is also a risk of transmission through blood donors and transplanted organs [7]. Seroprevalence of HEV in the general population in Europe varies between 2.2\%-52.2\% [8,9], whereas it ranges between 8 and $43 \%$ among

Correspondence to: Dr. Mohsen El Kossi, E-Mail: Mohsen.elkossi@nhs.net solid organ transplantation [10]. Due to the considerable risk of chronic hepatitis and/or liver cirrhosis in solid organ transplantation with HEV, there is a growing interest in the optimal treatment of these cases. That risk varies between $60-80 \%$ [11,12] Few guidelines have been developed to help clinicians optimise treatment strategy for these cases [13-15]. One of the shortcomings of these guidelines is the scarcity of available robust evidence in this area. This left clinicians with some ambiguity in some areas of patients care. We here present a case of a kidney transplant recipient with chronic hepatitis E, which we successfully treated with Ribavirin. We will discuss challenges of this case management in the light of the available guidelines.

\section{Case Report}

A 25 years old Caucasian male patient had a pre-emptive deceased kidney transplant when he was 13 years old. The cause of renal failure was right nephrectomy because of congenital dysplasia of the right kidney and congenital obstruction of the left kidney with subsequent ureteric reimplantation. HLA mismatch was 100 and he did not develop any rejection episodes throughout the post-transplantation course. He was maintained on dual immunosuppression therapy of Tacrolimus and Mycophenolate mofetil at 500mg twice daily. Tacrolimus dose was adjusted to maintain Tacrolimus trough level between 3-8ng/mL, with an average of $4 \mathrm{ng} / \mathrm{mL}$. A rise of ALT was noted and peaked to 406 . He was a heavy alcohol drinker and was advised to cut his alcohol intake. This showed some improvement of ALT initially but remained higher than the reference level. He reported feeling tired and lethargic. Graft function was slowly progressing over time with serum creatinine around 190-220umol/l from base line 
average of $150 \mathrm{umol} / \mathrm{L}$. There was also progressive worsening of proteinuria which peaking at $725 \mathrm{mg} /$ mmol. A kidney biopsy was performed which revealed features suggestive of chronic antibody mediated rejection. Circulating antibodies showed donor-specific antibodies. Ultra sound scan of the liver was unremarkable. He was investigated for different causes of hepatitis including hepatitis B (HBV), hepatitis C (HCV), Cytomegalo virus (CMV) and Epstein Barr virus (EBV) without identifying a definite cause for the isolated ALT elevation. It took sometime before we requested Hepatitis E (HEV) IgG and IgM antibodies which returned positive. HEV PCR was positive with viral count of $6.01 \log$ copies $/ \mathrm{mL}$. We commenced Ribavirin six months following the plasma PCR result, at a dose of $600 \mathrm{mg} /$ day (body weight 76 Kilos and creatinine clearance $48 \mathrm{ml} / \mathrm{min}$ ). The patient has already been on Neorecormon at a dose of $4000 \mathrm{U}$ weekly because of renal anaemia. This dose was pre-emptively doubled on Ribavirin introduction (Fig. 1). Haemoglobin (Hb) was monitored weekly. $\mathrm{Hb}$ dropped to $60 \mathrm{~g} / \mathrm{L}$ despit progressive increases in Neorecormon weekly dose to $30000 \mathrm{U}$. Hb level failed to improve despite the substantial increase in erythropoietin dose. Therefore, we decided to reduce Ribavirin dose to 400 $\mathrm{mg} /$ day. This didn't help improve Hb level. HEV RNA became negative after five weeks of Ribavirin treatment in both bloods and stool samples. Fig. (2) shows ALT level changes with ribavirin treatment.

We had to stop ribavirin treatment completely 45 days from the start, due to failure to improve $\mathrm{Hb}$ level. Blood transfusion option with the associated allo-sensitization risks attached to this treatment supported ribavirin withdrawal decision.

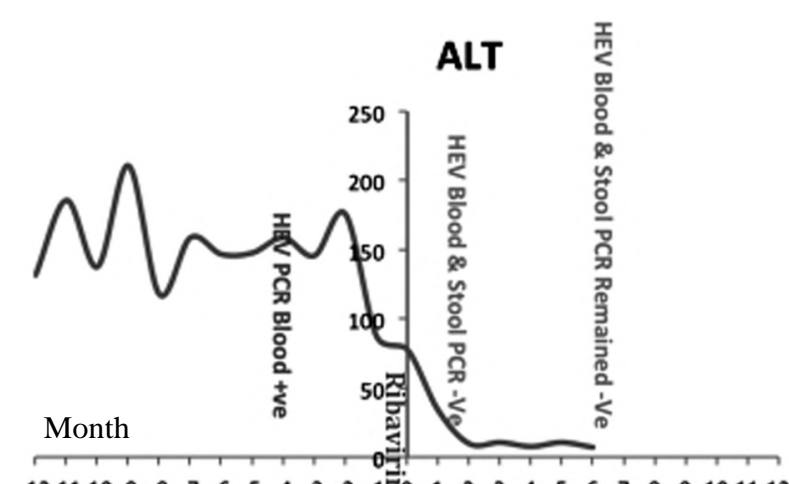

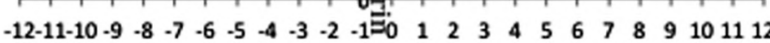

\section{ALT}

Fig. (1): Relationship between transaminase levels and viral clearance in blood and stool in response to ribavirin.

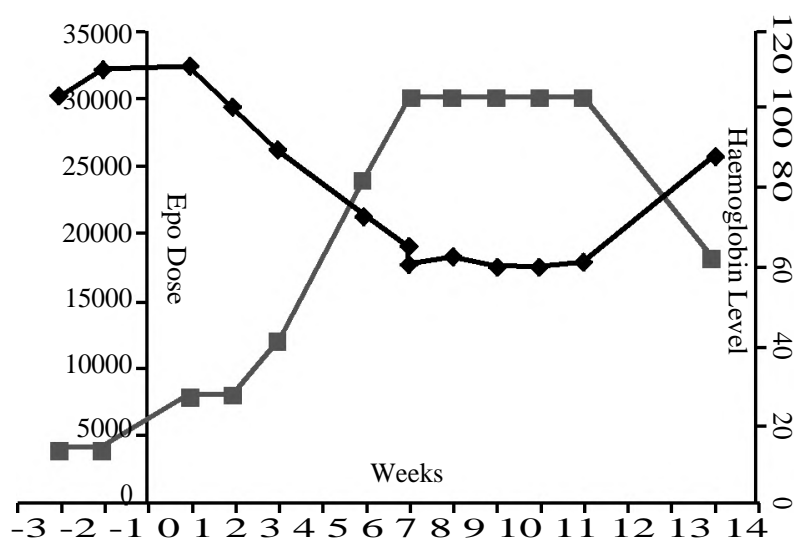

Fig. (2): Relationship between anaemia development and ribavirin treatment with increasing dose of Erythropoeitin injection.

\section{Discussion}

Our case has cleared Hepatitis E virus after 45 days of ribavirin treatment although not the full dose over the last two weeks of treatment course due to anaemia problem. This result was sustained for six months thus far. Viral clearance was achieved prior to the three months minimum recommended duration of ribavirin treatment, endorsed by British Transplantation Society (BTS) guidelines [13]. The reason for Ribavirin withdrawal was the profound anaemia that failed to respond to substantial increases of erythropoietin dose with Ribavirin dose reduction. BTS guidelines and many others suggest a strategic reduction in immunosuppression as a first step for the management of both acute and persistent Hepatitis E viral infection. One of the largest studies published by Kamar et al (2011) amongst others was the basis of this recommendation [11]. Interestingly, analysis of hepatitis E resolving patients in this study (29 out of 85 patients) did not need to have any significant changes in the type, dose or trough levels of immunosuppressive therapy [11]. The proportion of kidney transplant patients to the overall number of patients who responded to immunosuppression reduction (18 out of 56) was not reported. This puts the universal recommendation of immunosuppressive medication reduction to different organ transplantation into question. More interestingly, the role of immunosuppression was unclear in another relatively large cohort of patients with persistent hepatitis E treated with Ribavirin (59 patients) [16]. The authors' comment was clear that they could not fully assess the role of immunosuppressive regimens on virologic response, due to the small number of patients [17]. In another study from the same centre, $40.75 \%$ of patients with acute hepatitis E (11 out of 27) cleared the virus spontaneously 
without any modification of the immunosuppression except for one [18]. Four out of the remaining 16 patients $(25 \%)$ who were liver transplant recipients cleared the virus with significant reduction of Tacrolimus trough level from 13 to $6.6 \mathrm{ng} / \mathrm{mL}$. Such substantial dose reduction of Tacrolimus could be attained with minimal risk of graft rejection in liver transplantation [18]. Surprisingly Tacrolimus level differences within the same time interval were not reported for the remaining 12 viraemic patients. Whilst authors recommended cautious immunosuppressive reduction based on their observation, we believe that this strategy may not be universally applicable for all types of solid organ transplantation equally.

Of note, the diagnosis of HEV in this study was after a median interval of 49.5 (1-168) months. The average Tacrolimus level reported of 11.9ng/ $\mathrm{mL}(9-26)$ is exceptionally higher than the expected recommended target at this stage post kidneytransplantation. This level would probably require dose reduction irrespective of HEV status. On the other hand, Tacrolimus levels achieved in Kamar et al., case series after dose reduction averaged 7.9 compared to 10.1 at base line [11]. Again, this level is near to the higher end of the current recommended tacrolimus target in stable kidney transplant graft function by most centres after few month of transplantation.

In our case, we were unable to reduce the immunosuppression dose because of the high risk of graft loss with ongoing chronic antibody-mediated rejection and circulating donor-specific antibodies. Different Tacrolimus levels in these case series raise a question about the safe level of immunosuppression medications reduction even in the immunologically low risk patients. Kamar and colleagues [19] suggested Tacrolimus dose reduction to achieve a trough level of $<5 \mathrm{ng} / \mathrm{mL}$ and we are unclear about the evidence supporting this recommendation? Noteworthy is that in our case Tacrolimus trough level was averaging $4 \mathrm{ng} / \mathrm{mL}$ without any immunosuppression dose reduction.

Of interest, Ribavirin treatment is the recommended agent in the guidelines. Many case series reported also successful sustained virologic response with Ribavirin treatment. We have achieved the same result in our case, albeit with the challenge of anaemia development which was encountered in most of the case series and well recognised side effect of Ribavirin treatment. Interestingly most of the published cases in HEV infections in kidney transplantation did have allograft dysfunction with the potential of having renal anaemia prior to the
Ribavirin use. Our case was not any different; with an eGFR of $37 \mathrm{ml} / \mathrm{min}$. He was already on erythropoietin injections prior to the start of ribavirin (4000 units weekly). This might explain the exceptionally higher than usual erythropoietin doses (400unit/kg/week) required helping improve haemoglobin level in our case.

Luckily, our case cleared the virus from both blood and stool earlier than the minimum recommended duration for Ribavirin therapy. He cleared the virus in 45 days earlier than the recommended 3 month. Because of the persistent anaemia, we had to withdraw Ribavirin earlier than planned. Our case has a sustained virologic response in both stool and blood, 6 months following Ribavirin withdrawal. Weekly blood and stool check of hepatitis $E$ viral load after the first month of Ribavirin treatment facilitated this decision. The virus was not detected in two consecutive weeks in both stool and blood. This observation may raise the question about the minimum effective duration required for Ribavirin treatment in patients with kidney transplantation. The minimum of three months treatment was quoted from the case series published in 2014 by Kamar et al., [16]. Interestingly, they referred to viral clearance after one and three months of ribavirin treatment, but there was no mention of the virologic response in the interval between these two time points. They also referred to some cases responding to ribavirin treatment before the end of 3 months, and they maintained a sustained virologic response comparable to those treated with more than three months. More interestingly, 32 patients $(64 \%)$ had viral clearance by the end of the first month of treatment. The information from this study and the experience we have from our case attract special attention to kidney transplantation patients with persistent hepatitis E virus infection. The minimum three months of Ribavirin therapy to achieve a sustained virologic response might not be applicable in all cases. Earlier Ribavirin withdrawal may be indicated with reduced anticipated risk of anaemia in these patients especially with impaired kidney function and concomitant mycophenolate mofetil use. The optimum timing for Ribavirin start or the minimum duration required to achieve sustained viral clearance with low risk of relapse remains unclear. Until we have more robust evidence to answer these questions, we wonder whether a weekly monitoring of viral response in both blood and stool in these cases with Ribavirin withdrawal on two consecutive negative results would be an alternative to the current recommendation. This would probably be supported by having a 0.5 to $1 \log$ copies $/ \mathrm{mL}$ reduction of viral load at day 7 of Ribavirin treat- 
ment as suggested by some authors [20]. It may be difficult to answer this question abased on the available limited evidence.

Another interesting finding in our patient is the development of donor-specific antibodies. It was unclear whether there is any link between this finding and persistent hepatitis $\mathrm{E}$ viral infection. HEV is well known to have extrahepatic manifestations [21] and whether it could also have an immune modulating effect is uncertain. We were unable to establish such a relationship in our case because we did not hold any historical antibody results or blood samples prior to the HEV infection. Of relevance, donor specific antibodies persisted after successful virologic clearance probably refuting this possibility. One final point about HEV treatment in solid organ transplantation is the successful use of a short course of intravenous immunoglobulin for the treatment of Guillain Barre neuropathy complicating a few of these cases. They were all acute cases of HEV infection and mostly immunocompetent patients $[\mathbf{2 2 , 2 3 ]}$. They cleared the virus successfully but it remains unclear whether this was spontaneous clearance or it was helped by the intravenous immunoglobulins use. This raises a question about the value of intravenous immunoglobulins as a potential alternative for those who have contraindications or failed responses to Ribavirin?

\section{Conclusions:}

Our case report may suggest more frequent monitoring of hepatitis E viral response to Ribavirin treatment in kidney transplantation cases. It suggests also early withdrawal of Ribavirin treatment following two consecutive weekly negative results of blood and stool in order to minimise the risk of ribavirin-induced anaemia. There might not be a need for immunosuppressive reduction to achieve sustained virologic response in these cases, so long as CNI drug levels remained within the current recommended targets based on the duration post kidney transplantation.

Authors declare no conflict of Interest related to this case report.

There was no funding or support received for the purpose of this case report.

\section{References}

1- KHUROO M.S and KAMILI S.: Aetiology, clinical course and outcome of sporadic acute viral hepatitis in pregnancy, J. Viral Hepat., 10: 61-69, 2003.

2- ECHEVARRÍA J.M., GONZÁLEZ J.E., LEWISXIMENEZ L.L., et al.: Hepatitis E virus infection in Latin America: A review, J. Med. Virol., 85: 1037-1045, 2013.
3- KAMAR N., BENDALL R., LEGRAND-ABRAVANEL F., et al.: Hepatitis E. Lancet, 379: 2477-2488, 2012.

4- ABRAVANEL F., LHOMME S., CHAPUY-REGAUD S., et al.: Hepatitis E virus reinfections in solid-organtransplant recipients can evolve into chronic infections, J. Infect. Dis., 209: 1900-1906, 2014.

5- KAMAR N., SELVES J., MANSUY J.M., et al.: Hepatitis $E$ virus and chronic hepatitis in organ-transplant recipients, N. Engl. J. Med., 358: 811-817, 2008.

6- SMITH D.B., PURDY M.A. and SIMMONDS P.: Genetic variability and the classification of hepatitis e virus. J. Virol., 87 (8): 4161-9, 2013.

7- HARVALA H., HEWITT P.E., REYNOLDS C., et al.: Hepatitis E virus in blood donors in England, 2016 to 2017: from selective to universal screening. Euro. Surveill, 24 (10), 2019.

8- HARTL J., OTTO B., MADDEN R.G., et al.: Hepatitis E seroprevalence in Europe: A meta-analysis. Viruses, 6; 8 (8). https://doi.org/10.3390/v8080211, 2016.

9- MANSUY J.M., BENDALL R., LEGRAND-ABRAVANEL F., et al.: Hepatitis E virus antibodies in blood donors, France. Emerg. Infect. Dis., 17: 2309-2312, 2011.

10- MARION O., ABRAVANEL F., LHOMME S., IZOPET J. and KAMAR N.: Hepatitis E in Transplantation. Curr. Infect Dis. Rep., 18 (3): 8, 2016.

11- KAMAR N., GARROUSTE C., HAAGSMA E.B., et al.: Factors associated with chronic hepatitis in patients with hepatitis $\mathrm{E}$ virus infection who have received solid organ transplants. Gastroenterology, 140 (5): 1481-9, 2011

12- MOAL V., LEGRIS T., BURTEY S., et al.: Infection with hepatitis $\mathrm{E}$ virus in kidney transplant recipients in southeastern France. J. Med. Virol., 85: 462-471, 2013.

13-https://bts.org.uk/wp-content/uploads/2017/06/BTS HEV Guideline-FINAL

14- TEH DOUCETTE K.: Viral hepatitis: Guidelines by The American Society of Transplantation Infectious DiseaseCommunity of Practice. Clin. Transplant., 28: e13514, 2019.

15- LEVITSKY J. and DOUCETTE K.: AST Infectious Diseases Community of Practice. Viral hepatitis in solid organ transplantation. Am. J. Transplant. Mar., 13 (Suppl 4): 147-68, 2013.

16- KAMAR N., IZOPET J., TRIPON S., et al.: Ribavirin for chronic hepatitis $\mathrm{E}$ virus infection in transplant recipients. N. Engl. J. Med., 370 (12): 1111-20, 2014.

17- HARRABI H. and MAALOUL I.: Ribavirin for Chronic Hepatitis E Virus Infection. N. Engl. J. Med., 370; (25): 2446-48, 2014.

18- KAMAR N., ABRAVANEL F., SELVES J., et al.: Influence of immunosuppressive therapy on the natural history of genotype 3 hepatitis-E virus infection after organ transplantation. Transplantation, 89 (3): 353-60, 2010.

19- KAMAR N., MARION O. and IZOPET J.: When Should Ribavirin Be Started to Treat Hepatitis E Virus Infection in Transplant Patients? Am. J. Transplant., Feb; 16 (2): 727, 2016. 
20- KAMAR N., LHOMME S., ABRAVANEL F., et al.: An Early Viral Response Predicts the Virological Response to Ribavirin in Hepatitis E Virus Organ Transplant Patients. Transplantation, 99 (10): 2124-31, 2015.

21- PISCITANI L., LONGO M.O., GRABOCKA X., et al.: Extra-hepatic manifestations associated with Hepatitis and virus infection. G Ital Nefrol., 35 (2): 1-5, 2018.
22- ZHENG X., YU L., XU Q., GU S. and TANG L.: GuillainBarre syndrome caused by hepatitis E infection: Case report and literature review. BMC Infect. Dis., 18 (1): $50,2018$.

23- HIGUCHI M.A., FUKAE J., TSUGAWA J., et al.: Dysgeusia in a Patient with Guillain-Barré Syndrome Associated with Acute Hepatitis E: A Case Report and Literature Review. Intern. Med., 54 (12): 1543-6, 2015.

\section{الإصابة بفيروس الإلتهاب الكبلى الوبائى E بعل زراعة الكلى مراجعة المبادئ الإرشادية الوبانية}

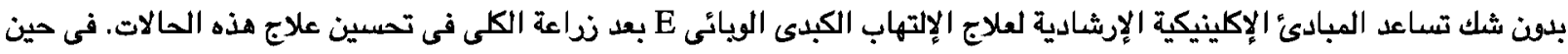

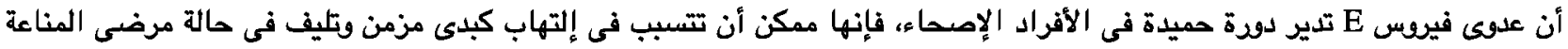

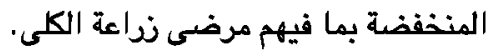

خيارات العلاج المتاحة لهذه الحالات تفتقر إلى دعم قوى الأدلة ومستمدة من عدد محدود من الحالات. لا توجد تجارب إكلينيكية كافية التساعد الأطباء فى صنع القرار.

يؤَدى هذا إلى بعض الثرات في المبادئ الإرشادية الحالية، وهذا يستدعى المزيد من الاهتمام. نتناول هنا حالة مريض نزع كلى، أصيب

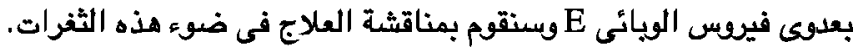

